\title{
Entre la pluralidad del lenguaje y la esencia de la pregunta. \\ Diálogo con el maestro Álvaro Moreno Rivas"
}

\author{
por Enrique Ferrer-Corredor**
}

"Mi alma es una orquesta oculta; no sé qué instrumentos tañen y chirrían, cuerdas y arpas, timbales y tambores, dentro de mí.

Solo me conozco como sinfonía"

Fernando Pessoa, Libro del desasosiego

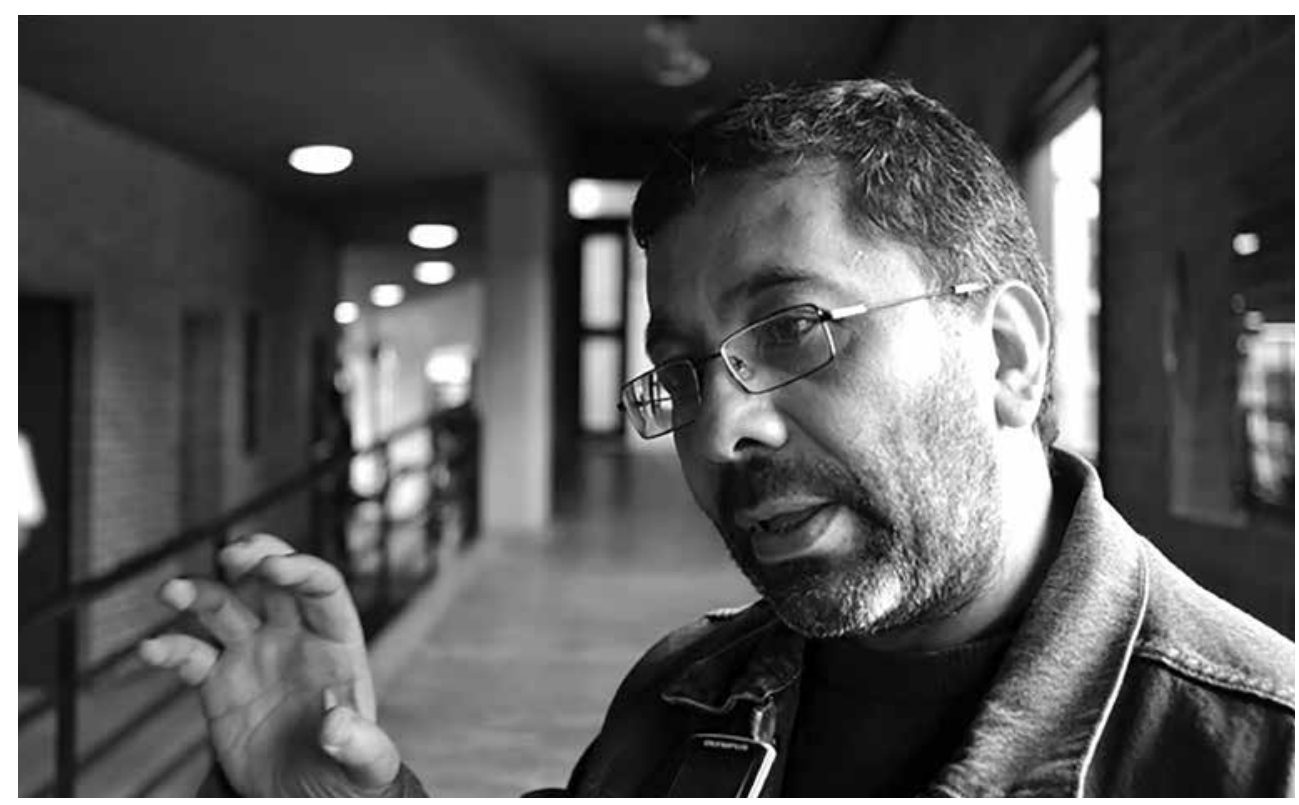

Fuente: CID, UNAL (2009)

Este encuentro es un pretexto en varios sentidos: el primero, hacer un homenaje a un gran maestro de la ciencia económica; el segundo, disfrutar de la sabiduría siempre interrogante de Álvaro; tercero, reencontrarnos, bajo la tutela de un maestro consagrado a la pregunta, con un tema fundante del debate sobre la justicia desde la teoría económica: la teoría del valor-trabajo.

Citar este artículo como: Ferrer-Corredor, E. (2020). Entre la pluralidad del lenguaje y la esencia de la pregunta. Diálogo con el maestro Álvaro Moreno Rivas. Revista Papeles, 11(22), 19-21.

* Profesor asociado de la Universidad Nacional, economista, físico, realmente, un ingeniero de la duda; pero sobre todo, un hombre íntegro, entregado a las preguntas, a la construcción de un mundo más justo, camino de concebir un ser humano más libre. Correo electrónico: amoreno65@yahoo.es

**: Director de la Revista Papeles. Correo electrónico: enfer48@hotmail.com 
1. Muy pocos economistas (profesores) asumen y mantienen el debate sobre la teoría del valor. Mucho menos desde la perspectiva de la herencia clásica de la teoría del valor-trabajo. ¿Cuál es su opinión sobre esta situación y sus consecuencias para el debate económico actual?

AMR: Me parece que la situación que usted señala es desafortunada. El debate sobre la teoría del valor prácticamente ha desaparecido de la enseñanza de la disciplina. Es difícil encontrar a algún colega de las nuevas generaciones con el libro de Maurice Dobb, Teoría del Valor y la Distribución desde Adam Smith debajo del brazo. Me atrevería a decir que ni siquiera han oído hablar del eminente profesor socialista de la Universidad de Cambridge. El silencio sobre las teorías del valor no significa que no exista la carga teórica y el peso de la teoría del valor en lo que los economistas y profesores discuten en la actualidad. De hecho, las propuestas de reforma tributaria, las medidas de regulación económica y las políticas macroeconómicas y distributivas se sustenta en una teoría del valor. La teoría subjetiva de la utilidad marginal. No distinguir entre valor y precio es una consecuencia de la teoría marginalista que se graba con letras de molde en los cerebros de los economistas modernos. Claramente, el proyecto monumental de Piero Sraffa que buscaba revivir la teoría del valor y de los precios clásica, una teoría objetiva del valor, también se expulsó de los salones de clase y de las discusiones de los economistas profesionales. Las razones de ello son esencialmente ideológicas. La teoría neoclásica o el marginalismo ganó la batalla por sus resultados puramente teóricos sobre la eficiencia de los mercados y la justificación de la tasa de ganancia del capital mediante la teoría de la productividad marginal de los factores productivos. Las matemáticas se convierten en dicho paradigma en un instrumento más ideológico que científico.
2. ¿Desde sus libros e investigaciones usted suele recurrir al diálogo con los temas de la teoría del valor-trabajo como referencia obligada para dar cuenta de los problemas de desigualdad económica e injustica social?

AMR: Aunque no es necesario hacer explícito desde el inicio el marco de análisis, claramente, cuando me refiero a los problemas distributivos, en lo sustantivo, mantengo un punto de vista clásico, donde la formación del valor y la distribución del producto obedecen a una teoría objetiva del valor, es decir, donde el salario real es una variable determinada por fuera del sistema económico o la tasa de ganancia se determina por la fijación de la tasa de interés, tal como lo sugirió Sraffa en su seminal libro Producción de mercancías por medio de mercancías. La teoría neoclásica, atrapada en la teoría del valor de la utilidad marginal y en el esquema de la oferta y la demanda, deja de lado el problema de la distribución funcional del ingreso, lucha de clases, y se concentra en la distribución personal, asociada a las decisiones individuales de los agentes.

3. ¿Los problema cruciales de la economía de hoy reclaman alguna teoría del valor, en particular, que dé cuenta del proceso de la producción, y no reducida como hoy, que se abandona el problema de la distribución del ingreso y la injusticia social por temas como la teoría del consumidor?

AMR: Considero que los enfoques modernos y los fundamentos de las teorías dominantes se sustentan en una teoría del valor. Las discusiones sobre temas económicos, ya sean relacionados con el desempleo, el salario real, la tasa de interés, la distribución del ingreso, la deuda pública o la política monetaria, están pegadas con el cemento de la teoría del valor que no distingue entre valor y precio; entonces, la principal consecuencia es que los precios de los bienes se determinan por la oferta 


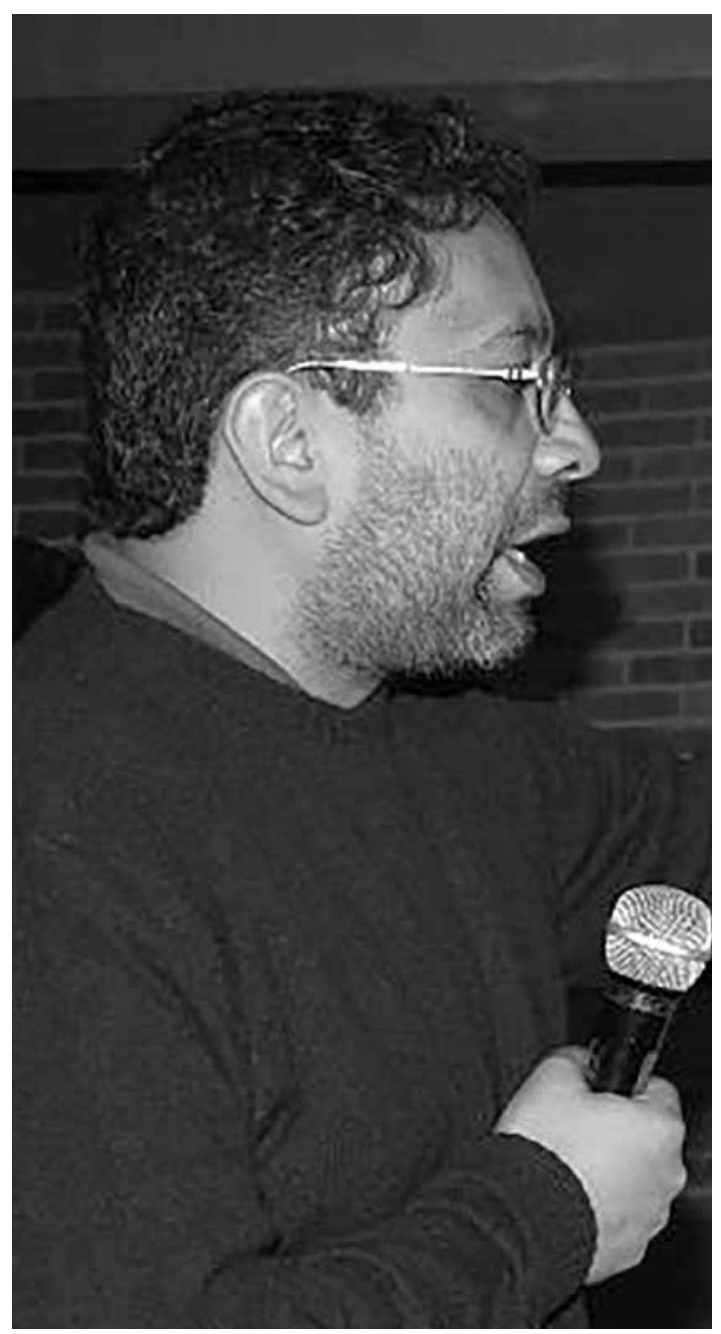

Fuente: CID, UNAL (2009)

y la demanda. Esta idea resume la sentencia central: los bienes tienen un precio si son escasos y todo se puede reducir a la misma unidad común: la utilidad. Soy un viejo profesor de economía ${ }^{1}$, educado en una época en la que estudiábamos las diferentes teorías del valor. Tal vez por ello echo de menos las discusiones sobre

1 El maestro Álvaro ha cedido su modestia a la palabra "viejo", él no es viejo, solo que estudió, estudiamos, bajo otros horizontes de la misma pregunta, su juventud se revela en la duda, en su reiteración por denunciar las falacias de las respuestas retóricas (nota del entrevistador). la tasa de explotación, la tasa de ganancia y el problema de la acumulación de capital y tendencia decreciente de la tasa de ganancia. Todos estos temas comunes a lo que William Baumol llamó la "dinámica magna" se abordaban con las teorías objetivas del valor trabajo. De hecho, algunos economistas, como Randall Wray, en un artículo de 1990, mostraba cómo la única teoría del valor consistente con la teoría monetaria de la producción de Keynes era la teoría del valor-trabajo. Tal vez tenga razón.

4. ¿Cuáles autores y tendencias de vanguardia recomienda usted para mantener vivo el debate de le teoría económica alrededor de la teoría del valor-trabajo como herramienta para el debate contemporáneo sobre la injusticia?

AMR: Me parece que en la actualidad, sin duda alguna, tenemos que promover el estudio riguroso de dos grandes economistas contemporáneos: Anwar Shaikh y Duncan Foley. Ellos han combinado una rigurosa conceptualización en las tradiciones clásicas y el uso de métodos modernos matemáticos, provenientes de otras disciplinas.

5. ¿Consejos para los jóvenes estudiantes de la ciencia económica hoy?

AMR: Tendría dos consejos. El primero de un gran escritor portugués, Fernando Pessoa: "Se plural como el universo". El segundo, de Richard Feynman, premio Nobel de Física: "La ciencia consiste en dudar de los expertos". Duden del ministro de hacienda y del gerente del Banco de la República; es la única aptitud científica sostenible en el largo plazo.

\section{Referencias}

CID, UNAL (2009). Imagen tomada del artículo: Crédito del FMI, señal contra los especuladores financieros, de Álvaro Moreno Rivas, Bogotá: CID. 